Social Science Information, 2007, in press.

Note: This is the final accepted manuscript. It has not been subjected to the final copyediting, fact-checking, and proofreading required for formal publication. It is not the definitive, publisher-authenticated version.

\title{
Rainer Reisenzein \\ What is a definition of emotion? \\ And are emotions mental-behavioral processes?
}

Klaus Scherer's aim in "What Are Emotions?" is to sensitize researchers to the importance of definitional issues in emotion research. One hundred and twenty years after James (1884), Scherer writes, there is still no generally accepted definition of emotion. The absence of such a definition has had a very negative effect on the field, for "without consensual conceptualization...of exactly what phenomenon is to be studied, progress in theory and research is difficult to achieve and fruitless debates are likely to proliferate" (p. 695). To achieve the desired consensus, Scherer proposes to take recourse to his well-known component-process theory and the definition of emotion that goes with it.

Scherer is certainly right that today's emotion researchers do not agree on the definition of emotion. However I disagree with his diagnosis of the implications of this state of affairs and I am skeptical of his proposed remedy.

\section{What is a definition of emotion and what is it good for?}

As usually understood, a definition is a specification of the essential or necessary (or, if such don't exist, at least the characteristic) features of a class of objects. Since Aristotle, two different bases of definitional necessity have been distinguished: linguistic conventions and the structure of language-independent reality. Traditionally the distinction is that between nominal and real definitions (e.g. Boyd, 1980). Presupposing this understanding of "definition", Scherer's metatheoretical position on the function and nature of a definition of emotion seems to be the following.

1. A definition of emotion is a prerequisite of meaningful theoretical and empirical research and the successful communication with others. In Scherer's words: a "systematic scientific approach" requires to "define central working concepts in [an] universal, invariant, and consensual fashion" (p. 696).

2. A definition of emotion is a nominal definition, that is, it is based on a linguistic convention concerning the meaning of the term "emotion" (analogously for terms for specific emotion, such as "joy", "fear" and "anger"). This second assumption is not explicitly made by Scherer but is strongly suggested by his comment that "definitions cannot be proven [but] need to be consensually considered as useful by a research community" (p. 724).

I disagree with both assumptions. The first reflects a misunderstanding of the function of definitions in science (Bunge, 1967). A (proper) definition of emotion is

Social Science Information (c) 2007 SAGE Publications (London, Thousand Oaks, CA and New Delhi), Vol 46(3), pp. 000000 . 
not necessary for fruitful research and successful communication. All that is needed for these purposes is a description that allows one to demarcate, at least roughly, the class of emotions, and thereby to identify one's research object to oneself and others. Such a working definition of emotion, as one may call it (Frijda, 1986: 1), is minimally provided by a list of typical examples of emotions (emotion types), as named in everyday language (e. g. Meyer, Reisenzein and Schützwohl, 2001 [1993]). This provides for a partial specification of the extension of the concept "emotion". Although a working definition of emotions that consists of nothing but a list of examples may seem too frugal or minimalist to be useful, no more may in fact be necessary (although more is possible; see Meyer, Reisenzein and Schützwohl, 1993). This conclusion is suggested by an important result of the so-called structuralist approach to theories (Balzer, Moulines, and Sneed, 1987), a prominent metatheoretical position on scientific theories. This result is that the listing of paradigmatic examples is the typical way in which the set of intended applications of a theory is specified in the empirical sciences. In fact a spicing-up of the proposed, minimalist working definition of emotions may be undesirable, because this will necessarily reduce its chances of agreement. In contrast, I am confident that widespread implicit agreement on a core set of paradigmatic examples of emotions exists among today's emotion researchers. We know that this consensus exists among lay people (e.g. Shaver et al., 1987).

Not only is an exact definition of emotion not necessary for meaningful research; it is in my view also not possible to define emotions correctly prior to empirical research (see also Frijda, 1986). The reason is that the quest for the nature (essential features) of emotions is itself a central question of emotion research. That this is indeed so is strongly suggested by the history of emotion psychology, which is full of attempts to empirically test proposed definitions of emotion (e.g. those of James or Schachter). The view that an emotion definition is a nominal definition would make this research activity look utterly irrational. These empirical tests, however, make perfect sense if an emotion definition is a real definition - an empirical claim about the essence of emotions (Reisenzein, 1994). Since the demise of logical empiricism and the rise of the "new scientific realism" philosophies of science, the view that some definitions - in fact, those of greatest interest to science - are after all a form of real definition has gained renewed respectability (for details, see Boyd, 1980, 1991, 2002; Griffiths, 1997). According to this view, a definition of emotion is an empirical hypothesis about the nature or constitution of the objects in the class picked out, more or less vaguely, by an extension-fixing device, such as the working definition of emotion suggested above. This hypothesis about the nature of emotion is always formulated against the background of a theory of emotion generation, whose truth it presupposes. In this sense, what an emotion is, is "ultimately determined by a theory that successfully accounts for paradigmatic emotional states" (Reisenzein and Schönpflug, 1992: 43; see also Frijda, 1986: 1). In sum, the consensual definition of emotion is not a precondition but the result of scientific research; and even then, it remains a revisable empirical hypothesis (Meyer, Reisenzein and Schützwohl, 1993; Reisenzein, 1994)..

\section{Emotions: mental states or mental-behavioral processes?}

In the light of the foregoing discussion, let us now briefly look at Scherer's proposal to resolve the problem of the definition of emotions by consensually adopting his component-process definition. According to this definition, emotions are processes of causally linked mental (appraisal, action tendency, subjective experience) and behavioral (physiological reactions, facial and vocal expression) elements. 
The first thing to note about the component-process definition is that this definition of emotion is not an uncontroversial working definition in the sense described earlier. Rather, it is a proper definition of emotion, which stands in clear opposition to all those definitions of emotion - probably still the majority - that take emotions to be mental states of one sort or another.

Proper definitions of emotion, I suggested, are real definitions, whose adequacy is decided (at least primarily) by empirical considerations. That this is also the case for Scherer's component-process definition of emotions can be seen by considering that this definition presupposes (i.e. entails) the truth of the component-process theory of emotion generation; that is, Scherer's model of the processes set into motion by (ultimately) emotion-producing stimuli. For suppose that certain assumptions of this theory turn out to be wrong. Specifically, suppose that research finds out that the expressive and autonomic changes that, according to component-process theory, are caused by specific appraisals are elicited by them only in special circumstances and are primarily determined by other, non-emotional factors. The correlation of the bodily and mental components of the posited emotion syndromes could then become so weak that emotion syndromes, as originally conceived of - patterns of reliably co-ocurring mental and bodily changes - cease to exist (although they fade into non-existence gradually rather than abruptly). Surely, non-existents cannot serve as the scientific referents of anger, fear, etc.

This is not merely a theoretical possibility. On the contrary, the empirical evidence that has accumulated over the past years suggests that it may just be true. For example, facial reactions of surprise seem to occur much less frequently in surprised people than would be required by the component-process definition of surprise (Reisenzein, 2000; Reisenzein et al., 2006). The evidence on the facial expressions presumably characteristic of other "modal" emotions (e.g. anger and disgust) is less clear-cut, but in my view points to the same conclusion. And the correlations typically found between the mental components of emotion syndromes and physiological reactions are soberingly low (e.g. Mauss, Wilhelm, and Gross, 2004). All this is not to deny that instances of full-fledged emotion syndromes of the sort postulated by component-process theory can occur. However, as Frijda suggested, these cases of emotions may be "but crystallizations in a stream of emotional response...that faithfully follows the continuous bed of relevance appraisals [which] goes on incessantly, mostly only felt by the person herself" (1986: 479).

But let us, for the sake of argument, assume the truth of Scherer's componentprocess theory of emotion, and thus the existence of the posited emotional processes. Even then, the identification of emotions with mental-behavioral processes is problematic. For if, as Scherer acknowledges (see also Scherer, 2004), the vernacular emotion words do not refer to syndromes but to mental states, then the corresponding component-process definitions do not have the same referents. Accordingly, definitions such as "anger = emotional response syndrome A" are false. And I cannot see the need for a conceptual revolution.

This suggests to me that emotions, whatever they are more precisely, are mental states, and are thus after all in the same class as sensations, beliefs and desires. Which, I feel, is as it should be.

Author's address: Rainer Reisenzein, Institute for Psychology, University of Greifswald, FranzMehringstrasse 47, 17487 Greifswald, Germany [e-mail: rainer.reisenzein@uni-greifswald.de] 


\section{References}

Balzer, W., Moulines, C.U. and Sneed, J.D. (1987) An Architectonic for Science: The Structuralist Program. Dortrecht: Reidel.

Boyd, R. (1980) "Materialism without Reductionism: What Physicalism does not Entail", in N. Block (ed.) Readings in Philosophy of Psychology, vol. 1, pp. 67106. Cambridge, MA: Harvard University Press.

Boyd, R. (1991) "Realism, Anti-Foundationalism, and the Enthusiasm for Natural Kinds", Philosophical Studies 61: 127-48.

Boyd, R. (2002) "Scientific Realism", Stanford Encyclopedia of Philosophy http://plato.stanford.edu/entries/scientific-realism/

Bunge, M. (1967) Scientific Research (Vol. 1). New York: Springer.

Frijda, N.H. (1986) The Emotions. Cambridge: Cambridge University Press.

Griffiths, P.E. (1997) What Emotions Really Are: The Problem of Psychological Categories. Chicago: University of Chicago Press.

James, W. (1884) "What Is an Emotion?", Mind 9: 188-205.

Mauss, I.B., Wilhelm, F.W. and Gross, J.J. (2004) "Is There Less to Social Anxiety Than Meets the Eye? Emotion Experience, Expression, and Bodily Responding", Cognition and Emotion 18: 631-62.

Meyer, W.-U., Reisenzein, R. and Schützwohl, A. (2001 [1993]). Einführung in die Emotionspsychologie, Band I [Introduction to the psychology of emotions, Vol. 1]. Bern: Huber. ( $2^{\text {nd }}$ edition)

Reisenzein, R. (1994). "Kausalattribution und Emotion [Causal attribution and emotion]. In F. Försterling \& J. Stiensmeier-Pelster (Eds.), Attributionstheorie. Grundlagen und Anwendungen, pp. 123-161. Göttingen: Hogrefe.

Reisenzein, R. (2000) "Exploring the Strength of Association between the Components of Emotion Syndromes: The Case of Surprise", Cognition and Emotion 14: 138.

Reisenzein, R., Bördgen, S., Holtbernd, T. and Matz, D. (2006) "Evidence for Strong Dissociation between Emotion and Facial Displays: The Case of Surprise", Journal of Personality and Social Psychology 91: 295-315.

Reisenzein, R. and Schönpflug, W. (1992) "Stumpf's Cognitive-Evaluative Theory of Emotion", American Psychologist 47: 34-45.

Scherer, K.R. (2004) "Feelings Integrate the Central Representation of AppraisalDriven Response Organization in Emotion", in A.S.R. Manstead, N.H. Frijda and A.H. Fischer (eds) Feelings and Emotions: the Amsterdam Symposium, pp. 136-57. Cambridge: Cambridge University Press.

Shaver, P., Schwartz, J., Kirson, D. and O'Connor, C. (1987) "Emotion Knowledge: Further Exploration of a Prototype Approach", Journal of Personality and Social Psychology 52: 1061-86. 